\title{
Matériasta
}

Revista Matéria, v. 15, n. 2, pp. 143-150, 2010

ISSN 1517-7076

http://www.materia.coppe.ufrj.br/sarra/artigos/artigo11208

\section{Modeling of work hardening behaviour of high Mn and low C polycristalline austenitic steel with twip effect}

\author{
M.O. Spindola; E.A.S. Ribeiro; B.M. Gonzalez; D.B. Santos \\ Metallurgical and Materials Engineering Department of Federal University of Minas Gerais. \\ e-mail: mirellespindola@hotmail.com ; gonzalez@demet.ufmg.br ; dsantos@demet.ufmg.br
}

\begin{abstract}
The steel of this work, $0.06 \mathrm{C}-25 \mathrm{Mn}-3 \mathrm{Al}-2 \mathrm{Si}-1 \mathrm{Ni}$ steel, presenting TWIP effect, was hot and cold rolled and then annealed at temperatures between 600 and $850^{\circ} \mathrm{C}$. The microstructure examination was focused in the recrystallization during annealing for different temperatures through optical and scanning electron microscopy. The volume fraction and recrystallized grain size measurements were performed. Tensile tests were conducted at room temperature. A polycrystalline model, based on micromechanics and working hardening theory, developed by Bouaziz et al., to predict the behavior of TWIP steels under different loading paths, was applied to the current steel. The results from the model are in good agreement with mechanical test and show a total elongation above $60 \%$, uniform elongation up to $55 \%$ and a tensile strength greater than $600 \mathrm{MPa}$, which highlights the potential of this steel for its various applications, mainly automotive industry. The model parameters are discussed and their limitations are presented.
\end{abstract}

Keywords: TWIP effect, annealing, modeling and simulation.

\section{INTRODUCTION}

One of the important characteristics of austenitic steels is their high capacity for strain hardening, which enables them to achieve high values of tensile strength with large plastic deformations. The austenitic steels containing high $\mathrm{Mn}$ content, and $\mathrm{Al}$ and $\mathrm{Si}$, in addition to these properties, they have lower density. It is precisely on these characteristic that makes this type of steel interesting for the automotive industry. The steel has a greater capacity for drawing and it is able to absorb high energy events in a vehicle crash [1].

The mechanisms responsible for this high strain hardening rate is related to the low stacking fault energy (SFE) presented by the austenitic phase. The value of the SFE controls the easiness which dislocations can carried out cross-slip. That is when the SFE is lower, it is easier to form of stacking faults and it is more difficult to cross-slip. This favors the mechanical twinning in relation to the dislocation gliding as a mechanism of plastic deformation of the steel $[1,2]$.

The increase in volume fraction of deformation twins creates additional obstacles for the dislocation, promoting a rapid work hardening of the steel. This phenomenon is known as TWIP (Twinning Induced Plasticity) effect.

Most austenitic steels, including Hadfield steels, that contain high manganese content (about 15 to $25 \mathrm{wt} \% \mathrm{Mn}$ ) have twinning mechanical deformation during cold rolling [2, 4], but the mechanism of deformation becomes dominant only in alloys with manganese concentrations in the order of $25 \%$ content of aluminum and silicon in the order of 2 to $3 \%$, plus the element carbon $[\underline{1}, \underline{2}]$. The TWIP effect occurs in a stable austenite, where the Gibbs free energy for the martensitic reaction is positive $(110$ to $250 \mathrm{~J} / \mathrm{mol})$ and the stacking fault energy is about $25 \mathrm{~mJ} / \mathrm{m}^{2}$. The increase in SFE is due to the high manganese content in the presence of aluminum and silicon. Aluminum, which is also present in small amounts in relation to manganese increases the energy of stacking fault of austenite and suppresses the martensitic transformation $\gamma_{\mathrm{fcc}} \rightarrow \varepsilon^{\mathrm{Ms}}{ }_{\text {hcp }}$, while silicon reduces the SFE and supports the martensite phase, resulting in mechanical twin during deformation $[\underline{4}, \underline{5}]$. On the other hand, the austenite with SFE less than $20 \mathrm{~mJ} / \mathrm{m}^{2}$ tends to transform into martensite $\varepsilon$ (hcp) when deformed [2].

To achieve a tensile strength of $700 \mathrm{MPa}$ and a uniform elongation more than of $50 \%$, characteristic of the TWIP steel, it is required a fine-grain microstructure obtained by cold rolling and recrystallization.

Several mathematical models have been developed and improved in an attempt to describe the physical hardening of steels, including steels that have TWIP effect [6-10]. In the present study, a physical model of the work hardening of the TWIP steel $(0.06 \mathrm{C}-25 \mathrm{Mn}-3 \mathrm{Al}-2 \mathrm{Si}-1 \mathrm{Ni})$ developed by Bouaziz et al. 
$[\underline{9}, \underline{10}]$ was used to describe the mechanical behavior during tensile tests. Thus, it is essential to model the mechanical behavior of steel through the knowledge of its microstructure and mechanical performance not only for understanding the phenomenology involved, but also for reduction of a series of laboratory experiments and industrial processing.

\section{MATERIALS AND METHODS}

The chemical composition of the steel investigated is listed in Table 1.

Table 1: Chemical composition of steel used (wt $\%)$.

\begin{tabular}{l|l|l|l|l|l}
\hline Element & $\mathrm{C}$ & $\mathrm{Mn}$ & $\mathrm{Si}$ & $\mathrm{Al}$ & $\mathrm{Ni}$ \\
\hline Content & 0.06 & 25 & 2 & 3 & 1 \\
\hline
\end{tabular}

Samples with dimensions of $100 \times 80 \times 30 \mathrm{~mm}$ were austenitized at $1,100^{\circ} \mathrm{C}$ for homogenization for 2 $\mathrm{h}$ and then quenching in water. These same plates were reheated at $1,100^{\circ} \mathrm{C}$ for hot rolling in four passes of the same deformation, reaching 50\% reduction in thickness. The hot rolled strip was machined to a thickness that is not found more traces of scale and divided into two equal parts to cold rolling. Then, it was promoted a sequence of 11 passes to achieve a total reduction of $43 \%$.

The annealing of cold rolled strip occurred at temperatures from 600 up to $850^{\circ} \mathrm{C}$. The total soaking time was set to $300 \mathrm{~s}$ for each temperature, and it was about $600 \mathrm{~s}$ for the heating time.

The microstructure of the samples was characterized by optical and scanning electron microscopy. For this examination, it was used nital $2 \%$ etchant. The analysis of the polished section was made in the section perpendicular to the rolling direction along the strip thickness. Recrystallized volume fraction was evaluated by point counts method. The grain size was evaluated by image analysis, measuring the area of each grain in micrographs obtained by scanning electron microscopy (SEM). It was measured at least two hundred grains per sample. The square root of the average value corresponds to the mean size of austenite grain. Further details of microstructural characterization are found in reference 11. After annealing, the samples were subjected to tensile testing at room temperature and a strain rate of $10^{-3} \mathrm{~s}^{-1}$ in an Instron machine, model 5582, using a $10 \mathrm{~mm}$ gauge length extensometer. The samples were machined according to ASTM A-370, $4.0 \mathrm{~mm}$ of diameter and a gage length of $25 \mathrm{~mm}$.

\section{RESULTS}

The model of the work hardening of steel with TWIP effect is well described in the literature $[\underline{9}, \underline{10}]$ and it was used in this work to modeling the behavior of the material under study during after tensile tests.

In summary, the model obeys the classical equation (1) between the true stress, $\sigma$, and the dislocations density of the steel, $\rho$ :

$$
\sigma=\sigma_{0}+\alpha \cdot M \cdot \mu \cdot b \cdot \sqrt{\rho}
$$

$\mathrm{M}$ is the Taylor factor and is equals:

$$
\gamma=M . \varepsilon
$$

Therefore, it can be said that:

$$
M=\frac{d \gamma}{d \varepsilon}
$$

Where $\gamma$ is the shear strain, $\varepsilon$ is the true strain, $\mu$ is the shear modulus, $b$ is the Burgers vector and $\alpha$ is a constant of order unity, which depends on the strength of dislocation or dislocation interaction. In this study the value of $\alpha$ used is independent of strain and is equivalent to 0.4 [9] , although the work of Kocks and Mecking states that $\alpha$ may decrease slightly with increasing deformation [6]

The net result of competition between the generation of dislocation and their reduction due to the recovery is given by $[\underline{6}, \underline{9}]$ : 


$$
\frac{d \rho}{d \gamma_{g}}=\frac{1}{b . \Lambda}-f . \rho
$$

Where $\Lambda$ is the dislocation mean free path, $\mathrm{f}$ is a constant and $\gamma_{\mathrm{g}}$ is the shear strain by dislocation gliding. If the twins can be seen as impenetrable obstacles, it can be said that [9]:

$$
\frac{1}{\Lambda}=\frac{1}{d}+\frac{1}{t}+k \cdot \sqrt{\rho}
$$

Where $\mathrm{d}$ is the grain size of austenite, $\mathrm{t}$ is the average twins spacing and $k$ is a constant. In turn [7]:

$$
t=2 e \frac{(1-F)}{F}
$$

Where $\mathrm{F}$ is the twin volume fraction and $e$ is the average twin thickness. The twinning contribution to the total plastic shear strain is given by $[7,9]$ :

$$
d \gamma=(1-F) \gamma_{g}+\gamma_{t} d F
$$

Where $\gamma_{t}$ is the twinning shear deformation and is equal to $1 / \sqrt{2}$. And easily obtain that:

$$
\frac{d \gamma_{g}}{d \varepsilon}=M e^{m \varepsilon}-\gamma_{t} m
$$

Combining equations 3, 4 and 5, one can express the evolution of dislocation density as a function of shear strain:

$$
\frac{d \rho}{d \gamma_{g}}=\frac{1}{b}\left(\frac{1}{d}+\frac{F}{2 e .(1-F)}+k \sqrt{\rho}\right)-f * \rho
$$

Thus, using the equation 7 , one can obtain the equation 9 , which provides the variation of the dislocations density, $\rho$, as a function of strain, $\varepsilon$.

$$
\frac{d \rho}{d \varepsilon}=\left[\frac{1}{b}\left(\frac{1}{d}+\frac{F}{2 e .(1-F)}+k \sqrt{\rho}\right)-f^{*} \rho\right] *\left(M e^{m \varepsilon}-\gamma_{t} m\right)
$$
expression [ $[\underline{8}]$ :

In these equations, it is assumed that $\mathrm{F}$, the twin volume fraction, is given by the empirical

$$
F=1-e^{-m \varepsilon}
$$

Where $\mathrm{m}$ is a constant independent of deformation and represents the rate of shear-band formation at low strains. However, this parameter depends on the SFE and the strain rate, and it increases with the decrease of the SFE and with increasing strain, since both of these factors tend to favor the shear-band deformation mode relative to deformation by slip [ $[\underline{8}$ ]. Its value is related only to steel chemical composition and deformation temperature $[1, \underline{3}]$. In this study, it was used 1.95 for this parameter, which is in accordance with the order of magnitude found in other research [ $[\mathrm{B}]$.

Solving numerically the equation 8 , with the aid of a computer algebra system, one can obtain a function $\rho(\varepsilon)$, and finally solve the equation 1 and determine $\sigma(\varepsilon)$, corresponding to the modeling of tensile test. The values and meanings of the other parameters are listed in Table 2. 
Table 2: Values used for modeling.

\begin{tabular}{l|l|l}
\hline Parameters & \multicolumn{1}{|c|}{ Physical meaning } & \multicolumn{1}{c}{ Value } \\
\hline $\mathrm{b}$ & Burgers vector & $2.5 \times 10^{-10} \mathrm{~m}$ \\
\hline $\mathrm{d}$ & Grain size & $3.5-7 \mu \mathrm{m}$ \\
\hline $\mathrm{f}$ & Dynamical recovery & $2-3$ \\
\hline$\rho$ & Dislocation density & $10^{12} \mathrm{~m}^{-2}$ \\
\hline$\mu$ & Shear modulus & $72 \mathrm{GPa}$ \\
\hline $\mathrm{m}$ & Constant (proportional to SFE) & 1.95 \\
\hline $\mathrm{k}$ & Constant & $0.001-0.01$ \\
\hline $\mathrm{e}$ & Mean twin thickness & $1.0 \mu \mathrm{m}$ \\
\hline $\mathrm{M}$ & Taylor factor & 3 \\
\hline
\end{tabular}

\section{DISCUSSION}

The microstructure of steel is illustrated in Figure 1 for the conditions of cold-rolled (a) and annealed at $850^{\circ} \mathrm{C}(\mathrm{b})$. Besides, in Figure 2 is shown the microstructure of the steel annealed at 750 or $850^{\circ} \mathrm{C}$ after the tensile test. Some examples of tensile tests results are illustrated in Figure 4(a,b). The grain size in these cases is the range between 3.7 and $7.0 \mu \mathrm{m}$, respectively, for temperatures of 750 up to $850^{\circ} \mathrm{C}$. Stressstrain curves showed good ability to work hardening, combined with a high mechanical strength, special characteristics of this kind of steel. Furthermore, the results for the total elongation, strain hardening exponent, tensile strength and grain size are listed in Table 3. The Figure 3 illustrates the determination of the strain hardening exponent calculated using the Considère's criterion $(\mathrm{d} \sigma / \mathrm{d} \varepsilon=\sigma)$ and indicated by arrow.

Table 3: Experimental values obtained after the tensile test and the respective grain size

\begin{tabular}{c|c|c|c|c}
\hline $\begin{array}{c}\text { Annealing } \\
\text { Temperature }\left({ }^{\circ} \mathrm{C}\right)\end{array}$ & $\begin{array}{c}\text { Strain Hardening } \\
\text { Exponent }\end{array}$ & $\begin{array}{c}\text { Tensile Strength } \\
(\mathrm{MPa})\end{array}$ & $\begin{array}{c}\text { Total Elongation } \\
(\%)\end{array}$ & $\begin{array}{c}\text { Grain size } \\
(\mu \mathrm{m})\end{array}$ \\
\hline 750 & 0.42 & 705 & 61 & 3.7 \\
\hline 775 & 0.48 & 684 & 67 & 4.5 \\
\hline 850 & 0.54 & 694 & 69 & 7.0 \\
\hline
\end{tabular}

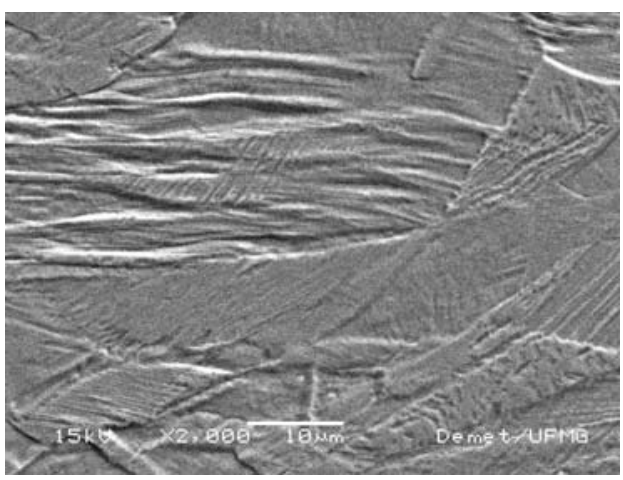

(a) Cold-rolled

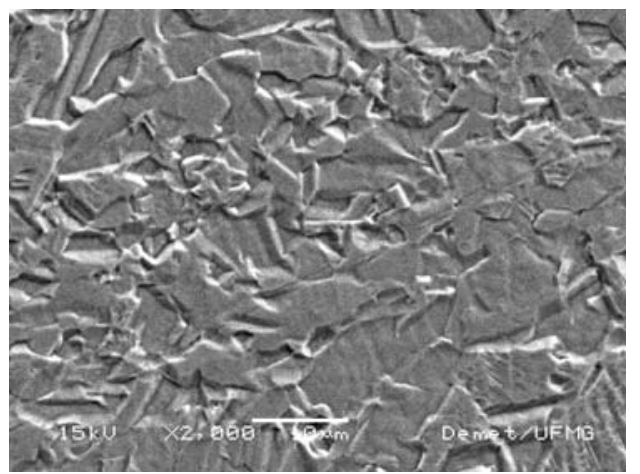

(b) Annealed at $850^{\circ} \mathrm{C}$

Figure 1: Microstructure of steel after cold rolling (a) and after annealing at $850^{\circ} \mathrm{C}$ (b). SEM micrographs. Nital $2 \%$ etched. 


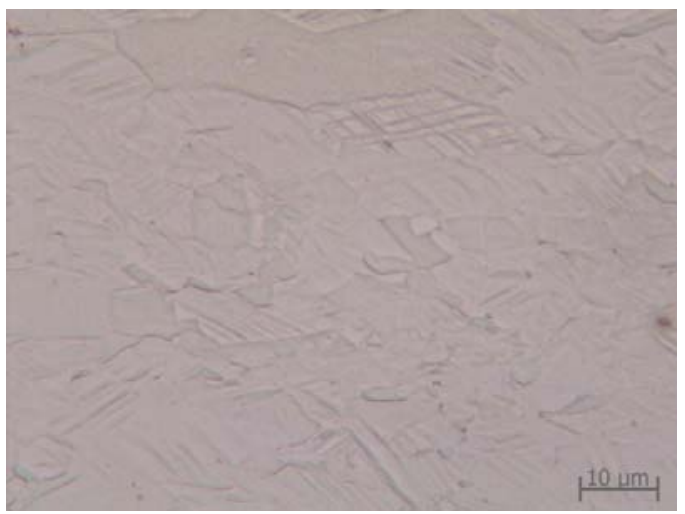

(a)

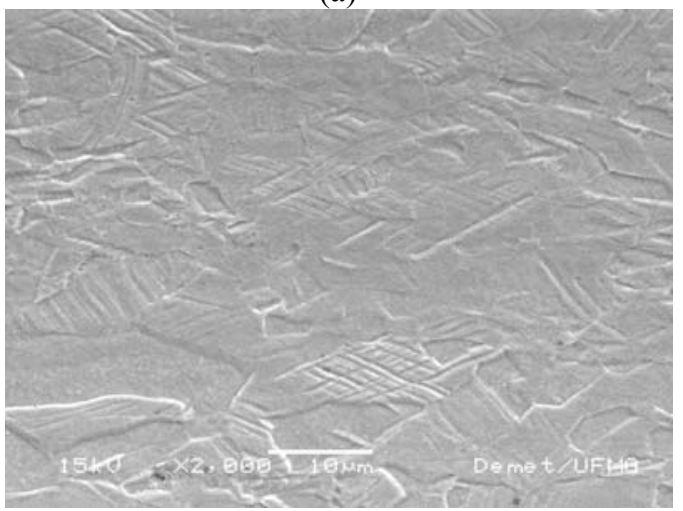

(c)

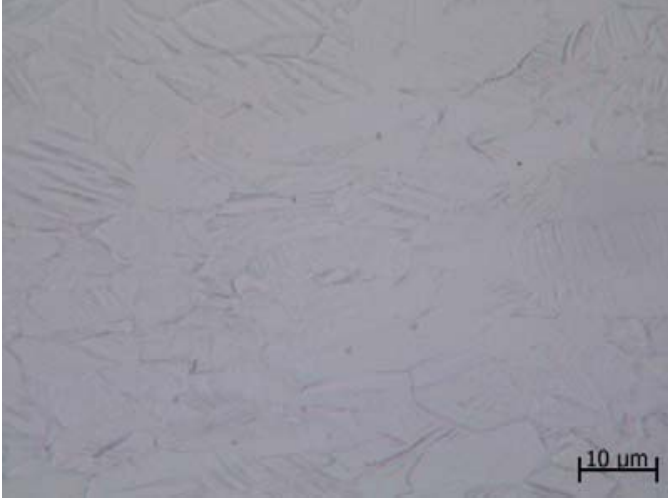

(b)

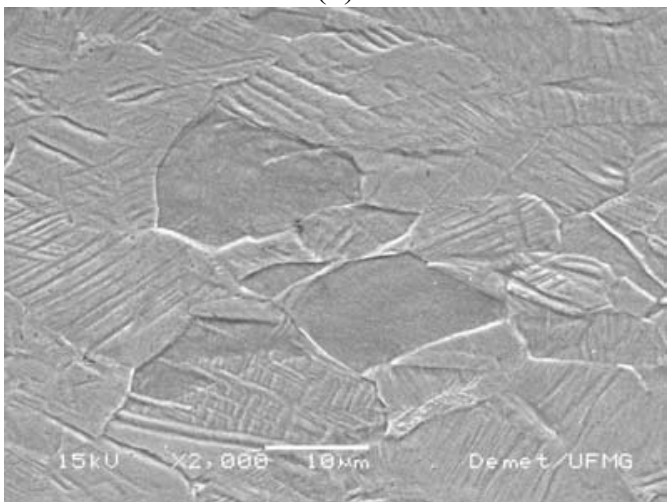

(d)

Figure 2: Microstructure of steel annealing at $750^{\circ} \mathrm{C}(\mathrm{a}, \mathrm{c})$ and $850^{\circ} \mathrm{C}(\mathrm{b}, \mathrm{d})$ after the tensile test, revealed by optical (a, b) and scanning electron microscopy (c, d). Nital 2\% etched.

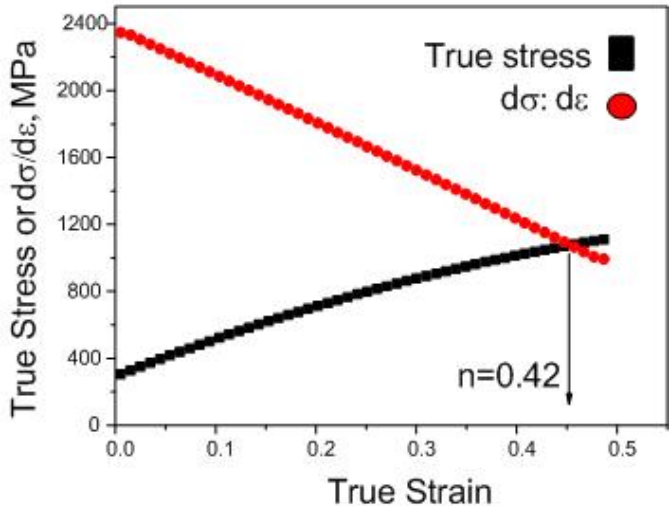

(a)

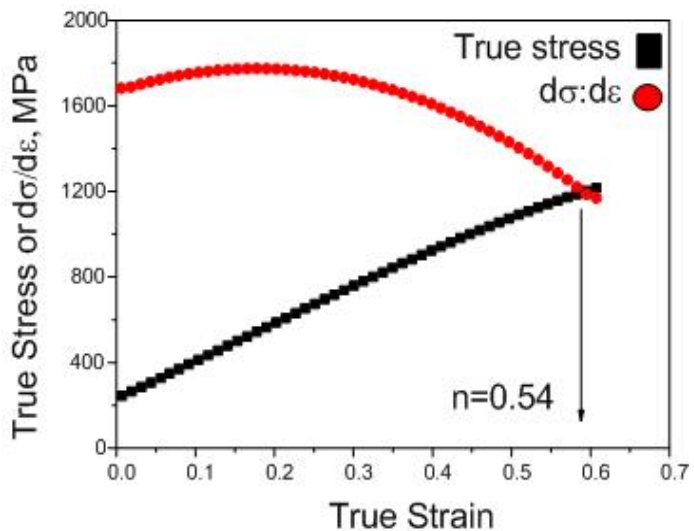

(b)

Figure 3: Calculation of the strain hardening exponent of the TWIP steel annealed at $750^{\circ} \mathrm{C}$ (a) and at $850^{\circ} \mathrm{C}$ (b).

Comparing the results obtained with other in the literature, for the same range of Mn content, there is a similarity. For example, the work of Kim et al. [ [5] and Mi et al. [12]. The increase of carbon content to $0.6 \%$ also implies the increase of strength, reaching values of tensile strength about $1,000 \mathrm{MPa}[\underline{4}, \underline{5}, \underline{9}, \underline{10}]$. In the present case, the carbon content is much lower, so the strength reaches around $700 \mathrm{MPa}$, also in agreement with $\mathrm{Mi}$ et al. [12]. The reduction in grain size leads to increase in strength, but the total elongation decreases [4]. However, looking at Figure 4(a,b) and analyzing the data in Table 3, the tensile strength of the samples annealed at 750 and $850^{\circ} \mathrm{C}$ is very close, although the grain size has increased when the temperature was raised. This happened because the sample annealed at $750^{\circ} \mathrm{C}$ the steel is not fully recrystallized, as shown in Figure 5. 


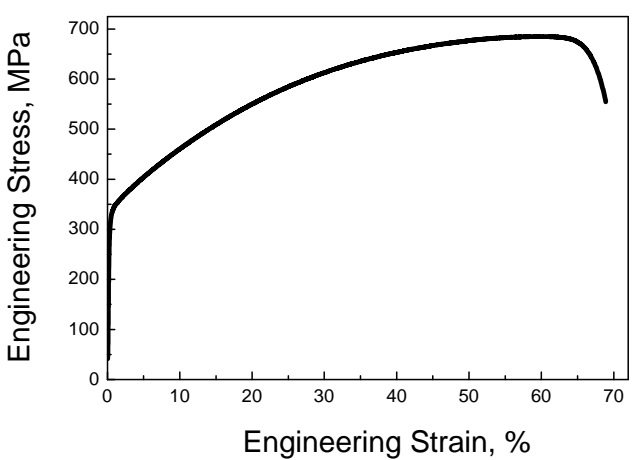

(a)

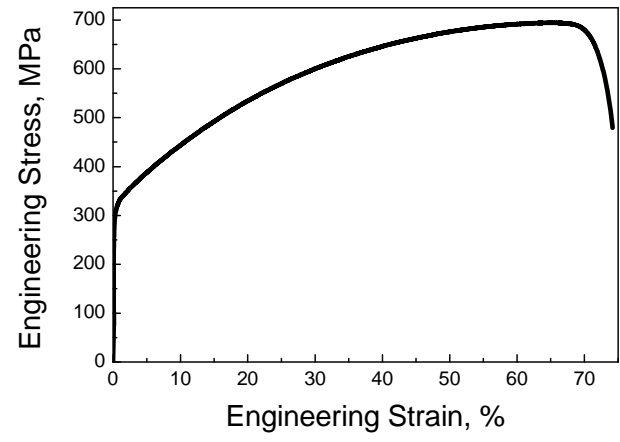

(b)

Figure 4: Engineering stress-strain curves of the samples annealed at $750^{\circ} \mathrm{C}$ (a) or $850^{\circ} \mathrm{C} \mathrm{(b).}$

As the annealing temperature increases, there is an increase in the total elongation. This is because a greater fraction of recrystallized grains in samples annealed at higher temperatures, reducing the initial dislocations density from the cold rolling condition, which allows a greater degree of strain hardening with the resulting delay in the formation of the necking down and fracture of the specimen.

Applying the model to the results of tensile test, it is possible obtain the curves illustrated in Figure 6 , which clearly show a good agreement between the model and the experimental results. However, the result is more representative for the material annealed at higher temperatures, since the model takes into account the initial state of the recrystallized material. Furthermore, it is noticeable that the fit is not in a good agreement with the experimental results for low strains.

The recrystallized volume fraction as a function of annealing temperature of TWIP steel is shown in Figure 5, indicates that the recrystallization is complete for temperatures above $800^{\circ} \mathrm{C}$. These results are consistent with those obtained by Bracke et al. [13] (annealing temperature $=700^{\circ} \mathrm{C}$ ), even though the authors worked with a steel cold-rolled with $50 \%$ reduction of higher carbon content (Fe-22Mn-0.6C), but with lower concentrations of alloying elements $(\mathrm{Mn}, \mathrm{Si}, \mathrm{Al}$, and $\mathrm{Ni}$ ), i.e., when compared to the steel of present study [11]. In this direction, Mi et al. [12] and Dini et al. [14] used alloys of similar chemical composition (Fe-31Mn-3Al-3Si) and found the recrystallization temperature of $700^{\circ} \mathrm{C}$ and $800^{\circ} \mathrm{C}$, respectively, while the grain growth already occurred above $800^{\circ} \mathrm{C}$.

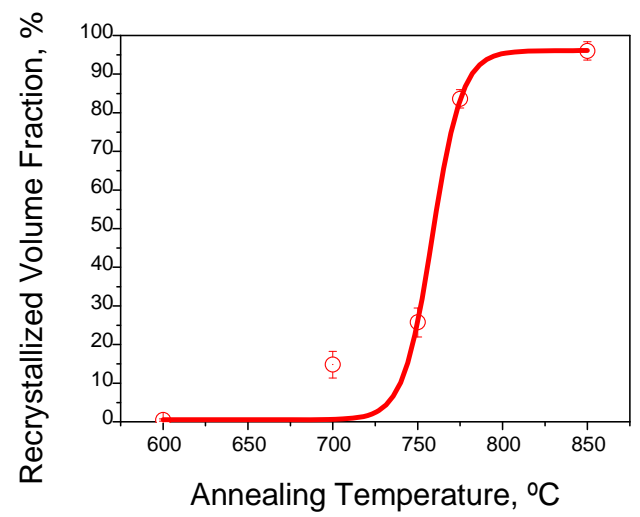

Figure 5: Recrystallized volume fraction versus annealing temperature for samples annealed between $600^{\circ} \mathrm{C}$ up to $850^{\circ} \mathrm{C}$. 


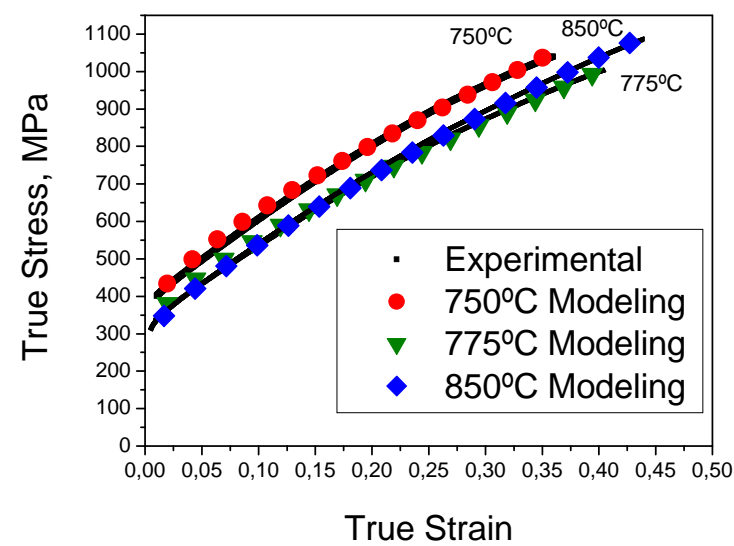

Figure 6: Curves of true stress versus true strain. Steel annealed at $750^{\circ} \mathrm{C}, 775^{\circ} \mathrm{C}$ and $850^{\circ} \mathrm{C}$.

The model suggests that the high work hardening rate of TWIP steel is due to the interaction between gliding dislocation and twins, where the twins act as strong obstacles to the dislocation motion. The twins promote a continuous refinement of the microstructure, reducing the dislocation mean free path. Therefore, the strain-hardening can be seen based on dynamic Hall-Petch (HP) effect [9]. However, the Sevillano work [15] stated that not only the HP effect must be considered, but should be increased by Bauschinger effect, that contributes to the plastic deformation by twinning due to high internal microstresses. Therefore, another explanation that may have caused the deviation from modeling approach could be justified by the high internal microstresses distribution [15].

Moreover, it is known that the deformation in tension of TWIP steel has two contributions, primarily from dislocation-dislocation and a reduction of dislocation mean free path due to mechanical twinning [16]. Therefore, before the start of mechanical twinning, slips occur initially by dislocations gliding and this mechanism control the flow behavior. Thus, the early stages of tension are controlled only by dislocation-dislocation interactions [16]. This is not consistent with the modeling, which is based on reducing the dislocation free path at all stages $[\underline{9}, \underline{10}]$. On the other side, as the grain size is reduced as a function of mechanical twinning formation, besides the dynamic HP effect, there is a limited dynamic recovery due to low SFE of the steel [17].

\section{CONCLUSIONS}

A physical model was used to simulate the mechanical behavior of TWIP steel under tensile testing. From the results the following conclusions can be withdraw: a) a good description were obtained of the behavior of a TWIP steel in tension using the present model; b) taking into account the partial recrystallization of the material, there is a small difference between the model and experimental result in the early stages of work hardening, i.e., in the beginning of the plastic deformation step.

\section{ACKNOWLEDGMENTS}

The authors thank FAPEMIG, TEC process number APQ-3318-5.07/07 and CNPq, process number $476377 / 2007-2$, for the financial support to carry out this research and research fellowships for the authors.

\section{REFERENCES}

[1] FROMMEYER, G., BRÜX, U., NEUMANN, P., "Supra-ductile and high-strength manganeseTRIP/TWIP steels for high energy absorption purposes", ISIJ International, v. 43, n. 3, pp. 438446, 2003.

[2] GRASSEL, O., KRUGER, L., FROMMEYER, G., MEYER, L.W., "High strength Fe-Mn-(Al,Si) TRIP/TWIP steels development - properties - application”, International Journal of Plasticity, v. 16, pp. 1391-1409, 2000. 
[3] VERCAMMEN, S., BLANPAIN, B., DE COOMAN, B.C., WOLLANTS, P., "Cold rolling behavior of an austenitic $\mathrm{Fe}-30 \mathrm{Mn}-3 \mathrm{Al}-3 \mathrm{Si}$ TWIP-steel: the importance of deformation twinning", Acta Materialia, v. 52, pp. 2005-2012, 2004.

[4] SCOTT, C., ALLAIN, S., FARAL, M., GUELTON, N., "The development of a new Fe-Mn-C austenitic steel for automotive applications", Revue de Métallurgie, n. 6, pp. 293-302, 2006.

[5] KIM, Y.G., KIM, T.W., HAN, J.K., CHANG, R.W. "Development of new austenitic Fe-Mn-Al-C steels for automotive applications", Key Engineering Materials, v. 84-85, pp. 461-472, 1993.

[6] MECKING, H., KOCKS, U.F. "Kinetics of flow and strain-hardening”, Acta Metallurgica, v. 29, pp. 1865-1875, Feb. 1981.

[7] REMY, L. "Kinectics of FCC deformation twinning and its relationship to stress-strain behavior", Acta Metallurgica, v. 26, pp. 443-451, June, 1977.

[8] OLSON, G.B., COHEN, M., "Kinectics of strain-induced martensite nucleation", Metallurgical Transactions A, v. 6A, pp. 791-795, April, 1975.

[9] BOUAZIZ, O., GUELTON, N., "Modeling of TWIP effect on the work-hardening", Materials Science Engineering A, v. 319-312, pp. 246-249, 2001.

[10] ALLAIN, S., CHATEU, J.P., BOUAZIZ, O., “A physical model of twinning-induced plasticity effect in high manganese austenitic steel”, Materials Science Engineering A, v. 387-389, pp. 143-147, 2004.

[11] DUARTE, D.M., RIBEIRO, E.A.S., SANTOS, D.B., "Comportamento mecânico do aço alto Mn e baixo C laminado a frio e recozido apresentando efeito TWIP”, In: 64 Congresso Anual da ABM, Belo Horizonte, MG, pp. 1-12, 2009.

[12] MI, Z.L., TANG, D., DAI, Y.J., WANG, H.Q., LI, S.S., "Influence of cold rolling reduction on microstructure and mechanical properties of TWIP steel”, Acta Metallurgica Sinica, v. 20, pp. 441447, December, 2007.

[13] BRACKE, L., VERBEKEN, K., KESTENS, L., PENNING, J., "Recrystallization behavior of an austenitic high Mn steel”, Materials Science Forum, v. 558-559, pp. 137-142, 2007.

[14] DINI, G., NAJAFIZADEH, A., UEJI, R., MONIR-VAGHEFI, S.M., "Improved tensile properties of partially recrystallized submicron grained TWIP steel”, Materials Letters, v. 64, pp. 15-18, 2010.

[15] SEVILLANO, J.G., "An alternative model for the strain hardening of FCC alloys that twin, validated for twinning-induced plasticity steel”, Scripta Materialia, v. 60, pp. 336-339, 2009.

[16] DINI, G., UEJI, R., NAJAFIZADEH, A., MONIR-VAGHEFI, S.M., "Flow stress analysis of TWIP steel via the XRD measurement of dislocation density", Accepted manuscript by Materials Science and Engineering A. doi:10.1016/j.msea.2010.01.033, January, 2010.

[17] UEJI, R., TSUCHIDA, N., TERADA, D., TSUJI, N., TANAKA, Y., TAKEMURA, A., KUNISHIGE., "Tensile properties and twinning behavior of high manganese steel with fine-grained structure", Scripta Materialia, v. 59, pp. 963-966, 2008. 